\title{
Intestinal parasitic infection-intensity, prevalence and associated risk factors, a study in the general population from the Uttarakhand hills
}

\section{Swapna Kotian, Munesh Sharma, Deepak Juyal, Neelam Sharma}

Department of Microbiology and Immunology, Veer Chandra Singh Garhwali Government Medical Sciences and Research Institute, Srinagar Garhwal, Uttarakhand, India

Address for the Correspondence: Ms. Swapna Kotian, Department of Microbiology and Immunology, Veer Chandra

Singh Garhwali Government Medical Sciences and Research Institute,

Srinagar Garhwal - 246 174, Uttarakhand, India. E-mail: kotian.swapna@gmail.com

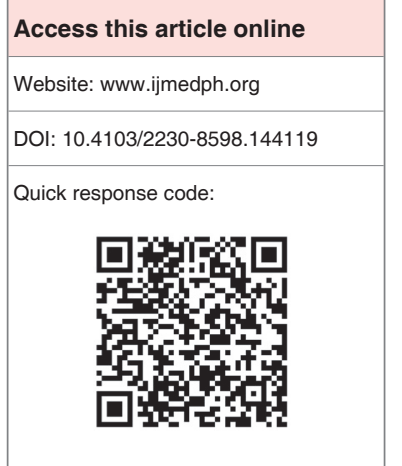

Background: Intestinal parasitic infection is an important public health problem in developing countries. Low socioeconomic conditions, lack of access to potable drinking water, poor personal hygiene and environmental sanitation are the factors associated with intestinal parasitic infection. Aim: The aim of this study was to estimate the prevalence of intestinal parasitic infections and identify the associated risk factors. Materials and Methods: Study was performed on 327 stool specimens of all age groups from August 2012 to May 2013. Specimen collected and examined with direct wet mount, formal ether sedimentation and salt flotation methods. Results: Out of the total 327 participants prevalence of intestinal infections was $11.62 \%$. Among the Protozoa, Giardia lamblia (3.06\%) was the most common, followed by Entamoeba histolytica (0.92\%). Hookworm (2.75\%) and Hymenolepis nana (2.14\%) were the most common helminthes found. Parasitosis was seen more in female $(17.07 \%)$ than male $(8.33 \%)$ and highest between 51 and 60 years $(22.22 \%)$ age group with risk factors like open defecation $(22.69 \%)$, untreated river water $(17.91 \%)$ and among people living in rural areas $(15.17 \%)$. Conclusion: There is a need to create awareness about safe drinking water, personal hygiene and environmental sanitation and to take urgent remedial steps to prevent and control intestinal parasitic infections.

Key words: Ascaris lumbricoides, Giardia lamblia, India, parasitosis

\section{INTRODUCTION}

Intestinal parasitic infection is endemic worldwide, and it represents a large and serious medical health problem in the developing countries with high prevalence rate in many regions. It is estimated that 3.5 billion people are affected, and 450 million are ill as a result of these infections, the majority being children. These infections cause morbidity and mortality along with other manifestations like iron deficiency anemia, growth retardation in children and other physical and health problems. ${ }^{\left[{ }^{11}\right.}$ Helminthic infection is also related to protein energy malnutrition, low pregnancy weight and intra uterine weight gain. The most common parasite causing infections globally are Ascaris lumbricoides (20\%), hookworm $(18 \%)$, Trichuris trichiura (10\%) and Entamoeba bistolytica $(10 \%) \cdot{ }^{\left[{ }^{[2]}\right.}$ Most of these are transmitted through soil, there route of transmission being faecally contaminated fingers or sometimes migrate through skin to intestine. ${ }^{[3]}$ Poor sanitation, scarcity of potable drinking water and substandard personal hygiene practices may contribute to the rapid spread of such infections. ${ }^{[4]}$ With increasing population, poor socioeconomic conditions, continuous urbanization and industrialization with unplanned reforestation and the climatic changes may be the various reasons for the emergence of previously unrecognized diseases. Ethenic food habits and tourism to exotic places have led to exposure of food borne parasitic infections. ${ }^{[5]}$ In India, the overall prevalence rate ranges from $12.5 \%$ to $66 \%$ with the prevalence rate for individual parasite varying from region to region. ${ }^{[9-12]}$

It has become important to know the disease burden of parasitic infestation in the general population residing in this area. One of the major drawbacks in the fight against the parasitic disease is the inability to prevent them by immunization as no effective vaccine is available 
currently against any parasitic disease. Thus, the present study aimed to evaluate the incidence and prevalence of intestinal parasitic infection in the general population in and around Srinagar Garhwal, Uttarakhand.

\section{MATERIALS AND METHODS}

This study was undertaken in the Department of Microbiology from August 2012 to May 2013 of all age groups and includes stool samples of the patients admitted to the wards as well as those attending the outpatient department of our tertiary care hospital with a total sample size of 327 . After the approval from Institutional Ethical Committee and obtaining written informed consent from the patient, stool samples were collected in wide mouthed sterile screw capped labeled containers without preservative. At the time of collection date of sampling, name of the patient, education, occupation, housing status, toilet facility, behavioral habits like hand washing practice after defecation and source of drinking water was also taken down in a performa.

The sample received were subjected to complete examination both gross and microscopy within 1-2 h of its collection. In gross examination consistency of the stool sample, presence of mucus, blood, intestinal worm and segments of the tapeworm was noted. Microscopic examination included saline and iodine wet mount, which was observed under $10 \times$ and $40 \times$ magnifications. Negative samples were re-examined by concentration technique like formal ether sedimentation (Allen-Ridley) and salt flotation technique. The wet mount was screened for the presence of ova and cyst of the parasite. Protozoa and helminthes were identified according to their morphological details (Garcia, 1998).

\section{RESULT}

A total of 327 stool samples were examined out of which 38 were found to have intestinal parasitic infection with a prevalence rate of $11.62 \%$. Various parasites identified among the study population were protozoans and helminthes. Among the parasites identified Giardia lamblia 10 (3.06\%), hookworm 9 (2.75\%) and Hymenolepis

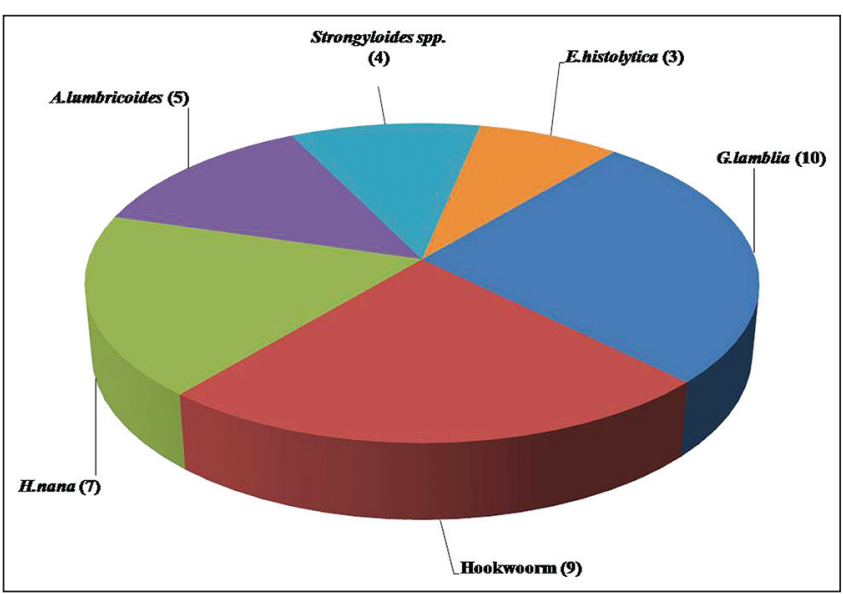

Figure 1: Characterization of the various parasites identified nana $7(2.14 \%)$ were the most common followed by, $A$. lumbricoides $5(1.53 \%)$, Strongyloides spp. $4(1.22 \%)$ and E. histolytica $3(0.92 \%)$. Figure 1 depicts the characterization of the various parasites identified.

It was noted that out of 38 positive samples, parasitosis was seen more in female patients $(17.07 \%)$ when compared to males $(8.33 \%)$. It was also noted that people who used open defecation $(22.69 \%)$, untreated river water (17.91\%), people living in rural areas $(15.97 \%)$ and those who were agriculturist by profession showed more prevalence of parasitic infection as depicted in Table 1. Parasitic infection was seen more in people belonging to age group between 51 and 60 years $(22.22 \%)$, followed by $11-20$ years $(18.75 \%), 41-$ 50 years $(11.43 \%), 31-40$ years $(11.36 \%), 0-10$ years $(10.61 \%)$, $61-70$ years $(9.09 \%)$, and $21-30$ years $(6.98 \%)$ as shown in Table 2. Figure 2 depicts the parasite distribution in various age groups. It was seen that in India the prevalence rate of intestinal infection ranges from $6.63 \%$ to $55.5 \%$ from the year 2002 to 2013 being depicted in Table 3.

\begin{tabular}{lccc}
$\begin{array}{l}\text { Table 1: Distribution based on gender, sanitation, } \\
\text { water source and residence } \\
\text { Positive (\%) }\end{array}$ & Negative & Total \\
\hline Sex & $17(8.33)$ & 187 & 204 \\
Male & $21(17.07)$ & 102 & 123 \\
Female & 38 & 289 & 327 \\
Total & & & \\
Sanitation & $11(5.29)$ & 197 & 208 \\
Closed & $27(22.69)$ & 92 & 119 \\
Open & 38 & 289 & 327 \\
Total & & & \\
Water treatment & $14(7.25)$ & 179 & 193 \\
Treated & $24(17.91)$ & 110 & 134 \\
Untreated & 38 & 289 & 327 \\
Total & & & \\
Residence & $15(8.20)$ & 168 & 183 \\
Urban & $23(15.97)$ & 121 & 144 \\
Rural & 38 & 289 & 327 \\
Total & & & \\
\hline
\end{tabular}

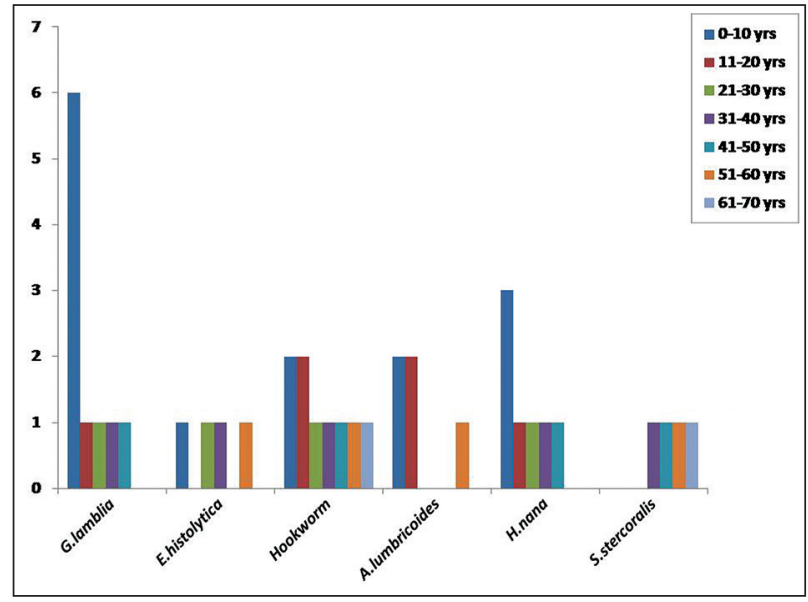

Figure 2: Parasite distribution in various age groups 


\section{DISCUSSION AND CONCLUSION}

Human parasitic infection is a global problem of enormous proportion with wide variation in intestinal parasite from region to region; different geographic areas, communities and ethnic groups even seasonal variation are also known. ${ }^{[7]}$ Knowledge of the distribution and extent of Intestinal parasitic infection in a given community is a prerequisite for planning and evaluating intervention program. The primary aim of this study was to identify the high-risk communities and formulate appropriate intervention measures. In the developing world intestinal parasitic infection is still an important cause of morbidity and mortality. ${ }^{[8]}$ The present study results showed the occurrence of several intestinal parasites of public health importance in people residing in this area. The prevalence was found to be $11.62 \%$ which is in agreement with the studies from Puducherry by Ragunathan et al. and from Lathur by Davane et al. but low when we compare it with the study from Vellore by Kang et al., showing a prevalence rate of $97.4 \%$. Various studies have shown that prevalence rate in India ranges from $12.5 \%$ to $66 \%$ with varying prevalence for individual parasites. ${ }^{\left[{ }^{212]}\right.}$ The wide variation in the prevalence of intestinal parasites may be due to variations in factors like quality of drinking water supply, sanitation and other environmental conditions.

\begin{tabular}{lccc}
\multicolumn{4}{l}{ Table 2: Parasitic distribution in varying age group } \\
\hline Age group & Positive (\%) & Negative & Total \\
\hline $0-10$ & $14(10.61)$ & 118 & 132 \\
$11-20$ & $6(18.75)$ & 26 & 32 \\
$21-30$ & $3(6.98)$ & 40 & 43 \\
$31-40$ & $5(11.36)$ & 39 & 44 \\
$41-50$ & $4(11.43)$ & 31 & 35 \\
$51-60$ & $4(22.22)$ & 14 & 18 \\
$61-70$ & $2(9.09)$ & 20 & 22 \\
$>70$ & 0 & 1 & 1 \\
Total & 38 & 289 & 327 \\
\hline
\end{tabular}

Srinagar Garhwal is situated on the bank of river Alaknanda originating from Himalayas, and serves as the main source of water for all purposes. However, being contaminated by organic and inorganic components which includes fecal waste which is flown into the river. There is no defined protocol for garbage disposal in the habitating areas along the river. Studies have shown that crowding and technical problems in disposal of sewage as the main factors determining parasitosis in water. ${ }^{[13]}$ Only $60 \%$ households have toilets, $10 \%$ use public toilets and rest 30\% defecate in the backyard of their house or in the open fields. The feces is exposed to scavenging animals, drying effects of sun and wind and during the rains being washed away contaminating the river water. ${ }^{[14]}$ High prevalence was seen in the population using untreated river water in comparison with those using filtered or boiled water this in accordance with the report of other authors. ${ }^{[15]}$

In the present study, it was observed that prevalence of intestinal parasitic infection was seen more among females (17.07\%) then the males $(8.33 \%)$. This can be better explained as, in addition to household work women in this region are also engaged in handling of livestock and in field work too and thus are comparatively more exposed to contaminated soil and water, a major predisposing factor for infection.

Giardia was the most common Protozoa identified in our study accounting for $3.06 \%$ and mostly seen in children which is in accordance with many studies conducted previously ${ }^{[16,22,28]}$ it gets transmitted by feco-oral route by drinking contaminated water as it is a common environmental contaminant of water supply. The water supply is really an important risk factor for the Giardiasis, and several large outbreak of Giardiasis have resulted from the contamination of drinking water supply with the human waste. Giardia cysts have been isolated from water supplies in different parts of the world. ${ }^{[17-21]}$

\begin{tabular}{|c|c|c|c|c|c|c|c|c|}
\hline \multirow[t]{2}{*}{ Year } & \multicolumn{2}{|r|}{ Sample } & \multicolumn{6}{|c|}{ Percentage of sample positive for } \\
\hline & $n$ & Percentage +ve & G. lamblia & A. lumbricoides & Hookworm & E. histolytica & H. nana & Strongyloides \\
\hline \multicolumn{9}{|l|}{2002} \\
\hline Kaur et al., (New Delhi) & 127 & 46.5 & 11.8 & - & 11 & - & - & - \\
\hline \multicolumn{9}{|l|}{2010} \\
\hline $\begin{array}{l}\text { Ragunathan et al. } \\
\text { (Puducherry) }\end{array}$ & 1172 & 34.56 & 7 & 43.21 & 28.89 & - & 7.66 & - \\
\hline Singh et al. (Kashmir) & 514 & 42.41 & - & 28 & - & - & - & - \\
\hline \multicolumn{9}{|l|}{2011} \\
\hline $\begin{array}{l}\text { Aher and Kulkarni } \\
\text { (Ahmednagar) }\end{array}$ & 624 & 30.4 & 13.5 & 1.9 & 0.9 & 3.9 & 4.5 & 0.6 \\
\hline Rashid et al. (Bareilly) & 320 & 22.81 & 6.25 & 9.68 & - & 2.5 & 2.18 & - \\
\hline \multicolumn{9}{|l|}{2012} \\
\hline Davane et al. (Lathur) & 211 & 6.63 & 33.3 & 45.4 & 27.2 & 66.6 & 36.3 & - \\
\hline Panda et al. (Bangalore) & 124 & 55.65 & 37.3 & 24.2 & 8.7 & 37.3 & 11.6 & - \\
\hline Bisht et al. (Gaziabadh) & 335 & 38 & 40.4 & - & 3.12 & 55.3 & 24.2 & - \\
\hline \multicolumn{9}{|l|}{2013} \\
\hline Present study (Uttarakhand) & 327 & 11.62 & 3.06 & 1.53 & 2.75 & 0.92 & 2.14 & 1.22 \\
\hline
\end{tabular}

$\mathrm{H}$. nana $=$ Hymenolepis nana, E. histolytica $=$ Entamoeba histolytica, A. lumbricoides = Ascaris lumbricoides, G. lamblia = Giardia lamblia 
The most common helminths infestation seen in our study was hookworm $2.75 \%$ followed by $H$. nana $2.14 \%$, A. lumbricoides $1.53 \%$, Strongyloides $1.22 \%$ and E. histolytica $0.92 \%$. This is in contrast to other studies in which Ascaris was the most common helminth. . $^{6,23,24,26,27,29,30]}$ Prevalence of hookworm infection can be attributed to walking barefoot in the fields as the infection results from penetration of the skin by filariform larva. ${ }^{[25]}$

This study showed that intestinal parasitic infection is a major public health problem and is directly related to poor personal hygiene, poor socioeconomic conditions and other factors. It has been shown that most endemic transmission of enteric infections among communities in developing countries is not primarily via water, but instead through other routes such as contaminated food, hands, and clothing. Among the interventional measures health education of school going children, maintenance of proper hand hygiene, provision of safe drinking water, proper waste disposal, identifying and treating infected as well as asymptomatic individuals are most important. The knowledge of prevalence will even strengthen or justify the prophylactic use of a broad spectrum anti-parasitic drugs particularly in children.

The study was limited to single sample observation. Perhaps, larger sample size and longitudinal studies with more parameters must be necessary for the continuation of this surveillance study to obtain an accurate understanding and cause of the parasitic burden of this area.

\section{REFERENCES}

1. World Health Organization. Control of Tropical Diseases. Geneva, Switzerland: WHO; 1998.

2. World Health Organization. Prevention and Control of Intestinal Parasitic Infections. Technical Reports Series. WHO; 1987. p. 575-88.

3. Blaser MJ, Ravindin JI, Guerrant RL, et al. Gastrointestinal tract infections. In: Richard VG, Hazel MD, Derek W, Mark Z, Peter LC, Ivan MR, et al., editors. MIMS Medical Microbiology. $4^{\text {th }}$ ed. Europe: Mosby Elsevier; 2008. p. 304-11.

4. Celiksöz A, Güler N, Güler G, Oztop AY, Degerli S. Prevalence of intestinal parasites in three socioeconomically-different regions of Sivas, Turkey. J Health Popul Nutr 2005;23:184-91.

5. Arora DR, Arora B. Medical Parasitology. New Delhi: CBS Publishers; 2007.

6. Ragunathan L, Kalivaradhan SK, Ramadass S, Nagaraj M, Ramesh K. Helminthic infections in school children in Puducherry, South India. J Microbiol Immunol Infect 2010;43:228-32.

7. Tedla S. Intestinal helminthiasis in man in Ethiopia. Helminthologia 1986;23:43-8.

8. Tanowitz HB, Weiss LM, Wittner M. Tapeworms. Curr Infect Dis Rep 2001;3:77-84.

9. Amin AB, Amin BM, Bhagat AP, Patel JC. Incidence of helminthiasis and protozoal infections in Bombay. J Indian Med Assoc 1979;72:225-7.

10. Ramesh GN, Malla N, Raju GS, Sehgal R, Ganguly NK, Mahajan RC, et al.
Epidemiological study of parasitic infestations in lower socio-economic group in Chandigarh (North India). Indian J Med Res 1991;93:47-50.

11. Singh P, Gupta ML, Thakur TS, Vaidya NK. Intestinal parasitism in Himachal Pradesh. Indian J Med Sci 1991;45:201-4, 200.

12. Singh S, Raju GV, Samantaray JC. Parasitic gut flora in a north Indian population with gastrointestinal symptoms. Trop Gastroenterol 1993;14:104-8.

13. Crompton DW, Savioli L. Intestinal parasitic infections and urbanization. Bull World Health Organ 1993;71:1-7.

14. Aher A, Kulkarni S. Prevalence of intestinal parasites in school going children in a rural community. Int J Biomed Res 2011;2:605-7.

15. Singh DS, Hotchandani RK, Kumar S, Seecatt JS, Srivastava PK, Udupa KN. Prevalence and pattern of intestinal parasitism: A rural community of Varanasi. Indian J Prev Soc Med 1984;15:1-8.

16. Dongre AR, Deshmukh PR, Boratne AV, Thaware P, Garg BS. An approach to hygiene education among rural Indian school going children. Online J Health Allied Sci 2007;6:1-6.

17. Wilson ME. In: Wallace RB, editor. Giardiasis in Public Health and Preventive Medicine. $14^{\text {th }}$ ed., Vol. 10. New York: Appleton and Lange; 1998. p. 252-4.

18. Zuckerman U, Armon R, Tzipori S, Gold D. Evaluation of a portable differential continuous flow centrifuge for concentration of Cryptosporidium oocysts and Giardia cysts from water. J Appl Microbiol 1999;86:955-61.

19. Shaw PK, Brodsky RE, Lyman DO, Wood BT, Hibler CP, Healy GR, et al. A communitywide outbreak of giardiasis with evidence of transmission by a municipal water supply. Ann Intern Med 1977;87:426-32.

20. deRegnier DP, Cole L, Schupp DG, Erlandsen SL. Viability of Giardia cysts suspended in lake, river, and tap water. Appl Environ Microbiol 1989;55:1223-9.

21. Hardie RM, Wall PG, Gott P, Bardhan M, Bartlett LR. Infectious diarrhea in tourists staying in a resort hotel. Emerg Infect Dis 1999;5:168-71.

22. Gujarathi UP, Goyal RC, Aher AR. Prevalence of intestinal parasitic infections in a rural community. Ind Med Gaz 1997;131:277-9.

23. Bisht $\mathrm{D}$, Verma $\mathrm{AK}$, Bharadwaj $\mathrm{HH}$. Intestinal parasitic infestation among children in a semi-urban Indian population. Trop Parasitol 2011;1:104-7.

24. Marothi Y, Singh B. Prevalence of intestinal parasites at Ujjain, Madhya Pradesh, India: Five-year study. Afr J Microbiol Res 2011;5:2711-4.

25. Kang G, Mathew MS, Rajan DP, Daniel JD, Mathan MM, Mathan VI, et al. Prevalence of intestinal parasites in rural Southern Indians. Trop Med Int Health 1998;3:70-5.

26. Davane MS, Suryawanshi NM, Deshpande KD. A prevalence study of intestinal parasitic infections in a rural hospital. Int J Recent Trends Sci Technol 2012;2:1-3.

27. Singh C, Zargar SA, Masoodi I, Shoukat A, Ahmad B. Predictors of intestinal parasitosis in school children of Kashmir: A prospective study. Trop Gastroenterol 2010;31:105-7.

28. Kaur R, Rawat D, Kakkar M, Uppal B, Sharma VK. Intestinal parasites in children with diarrhea in Delhi, India. Southeast Asian J Trop Med Public Health 2002;33:725-9.

29. Panda S, Rao UD, Ramasankaran K. Prevalence of intestinal parasitic infections among school children rural area of Vizianagaram. IOSR J Pharm Biol Sci 2012;3:42-5.

30. Rashid MK, Joshi M, Joshi HS, Fatemi K. Prevalence of intestinal parasites among school going children in Bareilly District. Natl J Integr Res Med 2011;2:35-7.

How to cite this article: Kotian S, Sharma M, Juyal D, Sharma N. Intestinal parasitic infection-intensity, prevalence and associated risk factors, a study in the general population from the Uttarakhand hills. Int J Med Public Health 2014;4:422-5.

Source of Support: Nil, Conflict of Interest: None declared. 